\title{
A Study on the Transformation of Corporate Finance Staff Under the Financial Shared Model
}

\author{
Yurong Gao
}

\author{
Shandong Women's University, Jinan, Shandong, 250010, China \\ *Corresponding author. Email:gaoyurong1975@163.com
}

\begin{abstract}
With the development and progress of the times, the application of the financial shared service model has become increasingly widespread and common. The financial shared service model has put forward new challenges to the previous financial systems and put forward higher requirements for financial staff. Traditional finance staff must make transformations and adjustments according to the needs of an enterprise to better complete and promote financial work. Based on the discussion of the direction of financial transformation, this paper analyzes problems existing in the process of financial transformation, and puts forward corresponding countermeasures, hoping to promote the smooth completion of transformation of finance staff under the financial shared model.
\end{abstract}

Keywords: Financial shared model, finance staff, transformation

\section{INTRODUCTION}

At present, with the rapid development of Internet technology, big data technology and AI technology, it has become an inevitable trend for the financial electronic data to develop towards big data, cloud computing, intelligence, and sharing. Domestic large and mediumsized enterprises have also started to implement financial shared service models successively, using it to realize the unified, standard and fast treatment of daily, common, repetitive, and standardized transactional activities in financial work, realize the transformation of the functions of the relevant departments of a group, and promote the simplification, optimization and unification of standards within the group, thereby improving the efficiency and benefits of the overall operation of the enterprise.

Based on Internet information technology, through process reorganization, and with the purpose of standardizing processes, optimizing structures, and creating value, financial shared service is a new type of financial management model that integrates the scattered financial business processes within the enterprise, establishes a unified data platform, and realizes the unified processing of transregional and transnational accounting business, and provides professional financial data services for different information users (customers) inside and outside the enterprise from the market perspective. It can be learned from the above definition that the core content of financial shared services is the unified processing and sharing of accounting across regions. From the perspective of current implementation effects of enterprises that have successfully implemented the financial shared service model, financial shared services have reduced the financial costs of enterprises, provided data to support the business decision-making of enterprises, and effectively promoted the revolutionary financial transformation and reform of traditional financial management models carried out by enterprises. Under this background, it is required that corporate finance staff should continuously adapt to the needs of the development of the times, break through the traditional conservative financial management model, abandon rigid thinking, promote corporate finance to transform from the accounting type to the management type, give full play to the role of financial management as the core of corporate management, accelerate the transformation of corporate finance staff, and enhance value creation ability to effectively respond to the impact and challenges brought by changes in the market environment.

\section{ANALYSIS ON THE TYPES OF TRANSFORMATION MODES OF FINANCE STAFF IN UNDER THE FINANCIAL SHARED MODEL}

Lots of examples of the successful transformation of corporate traditional finance staff show that under the background of the financial shared service model, the functions and structure of the corporate financial departments have changed a lot. Therefore, the staffing structure shall also be adjusted to avoid the waste of human resources. According to changes in the functions of the financial shared model and accounting functions, the traditional corporate finance staff can transform towards three directions: the first is strategic finance; the second is shared finance; and the third is business finance [1]. 


\subsection{Strategic Finance}

Strategic finance is the core function of financial management under the financial shared service model. Under the financial shared service model, strategic finance is the strategic supporter of enterprises, and also the main personnel that creates value for enterprises and conducts strategic risk management. Strategic finance staff needs to make corresponding financial decisions according to the development of the economic situation and the need of business transformation, and carry out corresponding management and maintenance of assets, capital operation, budget performance and other system structures, and conduct financial analysis and evaluation to provide basic data support for corporate strategy at the same time.

In the future, the development and growth of enterprises cannot be separated from the participation of strategic accounting. In the transformation of finance staff, outstanding personnel from traditional corporate finance staff can be cultivated as corporate strategic talents. This is because outstanding finance staff in enterprises has relatively high academic qualifications. They not only have theoretical knowledge and practical experience of corporate financial accounting, but also understand the strategic planning of corporate development. At the same time, they have relatively deep research on financial management and other economic businesses, with strong development potentials.

\subsection{Shared Finance}

Shared finance mainly undertakes the core functions of financial accounting. Shared finance staff should have certain financial accounting ability and be able to complete the centralized accounting of corporate finance to enable the improvement of corporate financial management efficiency. This requires that shared finance staff should both master knowledge such as financial knowledge, computer operation skills, financial information accounting, and new cost control methods, and have comprehensive skills such as project team communication, coordination, and organization. Only in this way can works related to be better completed.

Under the financial shared model, some finance staff can transform towards the direction of shared finance according to factors such as their own conditions. Shared finance staff should be engaged in the audit of accounting, which is, filling and reviewing vouchers, preparing financial statements, and conducting asset inspections. Meanwhile, shared finance staff should also have certain information technology means, and master review and approval points and other professional knowledge. During the advancement of the transformation of finance staff, enterprises can provide the following three options for finance staff: operation managers, technicians and operation and business personnel [2].

\subsection{Business Finance}

The main functions of business finance are to focus on the long-term strategic goals of the corporate development, and conduct comprehensive and detailed financial analysis, financial forecast, financial planning, financial monitoring, etc. of various aspects of the corporate development and operation, thus accelerating the pace of establishing an integrated system of business and finance. Provide all financial and business information for corporate managers and improve the feasibility and scientificity of development decision making. Those who transform from traditional finance staff to business finance staff should not only fully grasp traditional financial knowledge, but also master computer knowledge, statistical knowledge, management knowledge, etc. to better use financial tools such as information theory and control theory to carry out financial work. This requires that business finance staff must have a thorough understanding of the whole process of various corporate businesses to ensure the smooth development of all tasks.

In the financial shared model, in order to strengthen the integration between finance and business and achieve a good connection between finance and business activities, an enterprise requires that finance staff should not only master basic professional knowledge of accounting, but also understand its basic operating status, have a good understanding of business in aspects such as management, be able to go deep into the frontline business departments, deeply participate in corporate business activities and management processes, and learn the business operation norms and so on, and formulate or review financial points according to the operation situation, and organically integrate financial management with links such as corporate procurement, production, operation and sales to provide a reliable basis for the internal decision-making of the enterprise, and improve the level of each business of the enterprise [3].

\section{PROBLEMS EXISTING IN THE TRANSFORMATION OF FINANCE STAFF UNDER THE FINANCIAL SHARED MODEL}

\subsection{Insufficient Attention from Corporate Top Management and Weak Financial Transformation Concept}

Over the years, many enterprises have embarked on the road of financial transformation and have achieved certain results. However, at the current stage, the corporate top management fails to pay enough attention to the financial transformation issues. Affected by their own thinking levels and cognitive patterns, they are unaware of the importance of financial transformation. The attention of the corporate top management and the establishment of the 
supporting operating mechanisms and the evaluation and incentive mechanisms are crucial to whether the financial staff can transform smoothly and implement and give full play to their roles truly and effectively make the transformation smoothly. The insufficient attention of the corporate top management will certainly have negative impacts. In addition, the relevant corporate finance staffs have little knowledge related to their financial transformation, and do not cooperate with the financial transformation, and even think that this is a very troublesome and unnecessary thing. Therefore, during the implementation of corporate financial transformation, the effect is unsatisfactory.

\subsection{Lack of a Unified and Complete Internal Information System with Increasing Communication Costs}

Financial work plays an important role in an enterprise. Other parts of the enterprise are more or less related to its financial work. Under the financial shared model, the financial department and the business department are required to cooperate with each other. But actually, there are many contradictions between these two departments since they lack good communication, and have relatively low coordination, resulting in a dramatic increase in communication costs. Besides, the operation of the financial shared model must be built on the basis of information unification. However, the financial work of many modern enterprises fails to achieve this due to the lack of systems that can realize information unification within the enterprise [4]. As a result, in the daily operation of an enterprise, some of its information cannot be shared within the information system, and the timeliness of enterprise information is insufficient. And the lack of internal information systems leads to the reduction of management efficiency. Moreover, under the financial shared model, the corporate information security issue is also very important. If there is leakage of financial data, it will have a serious impact on the enterprise.

\subsection{Slow Talent Transformation Speed and Huge Training Needs}

After an enterprise builds its financial shared service center, higher requirements are put forward for the finance staff. After the establishment of the financial shared service center, the daily accounting of the enterprise will be completed by computers, which reduces the demand for financial accounting staff, and the transformation of finance staff is essential. However, at the current stage, accountants in China focus on the learning of financial professional knowledge, and are less exposed to and master knowledge in management accounting, management, and other aspects. Finance staff's professional abilities are not enough. For example, accountants are long engaged in accounting work, while financial shared model is the centralized management of finance, business and management. Accountants cannot adapt to such work and it is difficult to for them to adapt to the needs of financial transformation. Therefore, the comprehensive quality of finance staff needs to be improved, and enterprises should strengthen their training.

\section{SUGGESTIONS ON ACCELERATING THE TRANSFORMATION AND UPGRADING OF CORPORATE FINANCE STAFF UNDER THE FINANCIAL SHARED MODEL}

\subsection{Corporate Top Management Should Pay High Attention and Improve Their Understanding of Financial Transformation}

First of all, corporate top management should compare with the successful practice of excellent enterprises to find the gap and be fully aware of the urgent need and imperative of finance staff transformation under the financial shared model. In combination with their own actual characteristics, they should support financial transformation from all aspects, and improve the corporate organizational structure, operating mechanism, resource guarantee (including information construction, etc.), evaluation incentives, etc., to provide guarantees for the smooth transformation of finance staff [5].

Secondly, finance staff should change their thinking and concepts and improve their understanding of financial transformation. Enterprises should also strengthen publicity and education. They should increase the publicity and education of knowledge related to financial sharing and financial transformation, and further improve financial staff's ideological understanding level, especially that of relevant personnel of the financial department and business department who should learn the advantages of financial sharing through constant learning to cooperate actively in daily work.

\subsection{Establishment of Financial Information Shared Platform to Promote Business-finance Integration}

Under the financial shared model, the boundary of financial organizations is broken, the connection is constantly real-time, and various management activities of enterprises are added into the shared "big platform." Enterprises should emphasize the concept of sharing in their management and establish a financial information shared platform. Enterprises should take the corporate financial department as the basis and adopt an internal management model that is traceable, that is, based on the financial department, require the resources and capital movements of all departments to be filed at the financial 
department, establish a direct connection between the financial department and other departments, and relevant department can promptly obtain relevant data, thus maximizing the value of data, realizing the sharing of information among various departments, and reducing communication costs. At the same time, enterprises should strengthen communication between the financial department and the business department to promote the business-finance integration. In the daily business activities of an enterprise, the financial department and the business department should strengthen communication and contact, be good at thinking in each other's position, and communicate and penetrate under the common goal of seeking development for the enterprise to realize the good communication, coordination and cooperation between these two departments. In the meantime, the performance of the financial department and the business department should be gradually linked to enable staff of both departments to take the long-term goal of the enterprise as the development direction.

\subsection{Improvement of the Overall Quality of Financial Staff}

Under the financial shared model, optimizing and improving comprehensive abilities is one of the tasks that all corporate financial staff must do well.

Enterprises should build a need-oriented talent shared training model in combination with their own financial shared model and realize transformation and upgrading through the training of original financial staff. Firstly, professional financial sharing scholars can be hired to popularize the financial sharing concept in the financial team; secondly, the financial shared model of other outstanding enterprises can be actively learned through the communication and cooperation between enterprises and good experience can be used for reference in the enterprise. Finally, corporate financial staff should update their professional knowledge and expand their knowledge fields. They should improve their self-marketing and communication abilities, actively participate in contract and project management, corporate strategic management, business analysis, business budget management and other activities, and fully improve their comprehensive quality and ability [6]. In addition, operating skills of financial software such as shared service systems should be grasped and comprehensive analysis with the use of big data should be learned to enable the users to obtain useful information through real-time data analysis.

\section{CONCLUSION}

With the continuous progress of science and technology, the financial shared service model is still developing and being improved and its own value is still under constant development. It will inevitably develop towards a more advanced and in-depth direction and provide support and consulting services for business decision-making. After an enterprise's construction of the financial shared service model completes, traditional financial staff can transform towards the three directions of strategic finance, shared finance, and business finance. However, in the actual transformation, financial staff need to change their thinking, be able to respond quickly, train shared thinking, enrich knowledge reserves, and develop towards a comprehensive and more professional direction to develop themselves into compound talents and find a career path suitable for their career development. Only in this way can the financial staff find a suitable role in the general trend of transformation and play their value.

\section{REFERENCES}

[1] Yongqing GUO, A Study on the Business-Finance Integration of Chinese Enterprises [J]. Friends of Accounting, 2017, (15): 47-55.

[2] Yufen JIANG, Thinking on the Transformation of Traditional Finance Staff under the Financial Shared Form [J]. Accounting Learning, 2018 (20): 55+57.

[3] Yaling WANG, A Study on the Transformation of Corporate Finance Staff Based on the Financial Shared Model [J]. Tax Paying, 2019, 13 (16): 139.

[4] Chunling ZHANG, A Study on the Transformation of Corporate Finance Staff under the Financial Shared Model [J]. Money China (Academic Edition), 2019 (19): 170-171.

[5] Fen SONG, Construction of Business-Finance Integration Model Based on Financial Shared Platform [J]. Communication of Finance and Accounting, 2019 (02): $75-78$

[6] Guangyi CHEN, Discussion on Problems and Countermeasures of Financial Transformation Based on Financial Sharing [J]. Accounting Learning, 2019, (24): 67-68. 